\title{
BMJ Open Assessing the relationship between parental imprisonment in childhood and risk of sexually transmitted infections: a cohort study of US adults in early adulthood
}

\author{
Michael Roettger (D) , ${ }^{1}$ Brian Houle (D) ${ }^{1,2}$
}

To cite: Roettger M, Houle B. Assessing the relationship between parental imprisonment in childhood and risk of sexually transmitted infections: a cohort study of US adults in early adulthood. BMJ Open 2021;11:e038445. doi:10.1136/ bmjopen-2020-038445

- Prepublication history and additional materials for this paper are available online. To view these files, please visit the journal online (http://dx.doi. org/10.1136/bmjopen-2020038445).

Received 12 March 2020 Revised 25 February 2021 Accepted 04 March 2021

D) Check for updates

(C) Author(s) (or their employer(s)) 2021. Re-use permitted under CC BY-NC. No commercial re-use. See rights and permissions. Published by BMJ.

${ }^{1}$ School of Demography, Australian National University College of Arts and Social Sciences, Acton, Australian Capital Territory, Australia ${ }^{2} \mathrm{MRC} /$ Wits Rural Public Health and Health Transitions Research Unit (Agincourt), University of the Witwatersrand Faculty of Health Sciences, Johannesburg, Gauteng, South Africa

Correspondence to Dr Michael Roettger; mike.roettger@anu.edu.au

\section{ABSTRACT}

Objectives One in six young adults in the USA experiences parental imprisonment in childhood. Prior studies have associated parental imprisonment with risk of sexually transmitted infection (STI); however, potential data and methodological issues may have limited the reliability and accuracy of prior findings. Examining cumulative and longitudinal risk, we address several methodological limitations of prior studies and also examine comparative risk by respondent sex and ethnicity. We assess these associations using a range of control variables.

Design A national cohort study from the National Longitudinal Study of Adolescent to Adult Health using (1) a cross-sectional sample of adults at ages 24-32 years and (2) a longitudinal sample between ages 18 and 32 years. Both analyses estimate ORs for STI associated with parental imprisonment and examine variation by parent/ child gender and respondent ethnicity.

Setting In-home interviews in the USA at wave 1 (19941995), wave 3 (2001-2003) and wave 4 (2007-2009).

Participants 15684 respondents completing interviews at wave 1 (ages 12-18 years) and wave 4 (ages 26-32 years), including 8556 women, 3437 black and 2397 respondents reporting parental imprisonment.

Results Father-only imprisonment is associated with 1.22 higher odds ( $95 \% \mathrm{Cl}: 1.09$ to 1.37 ) of lifetime STI and 1.19 higher odds ( $95 \% \mathrm{Cl}: 1.01$ to 1.41 ) of STI in the past 12 months between ages 18 and 32 years, adjusting for familial, neighbourhood, individual and sexual risk factors. Maternal imprisonment is not associated with higher risk of lifetime STI after adjusting for confounders $(95 \% \mathrm{Cl}$ : 0.90 to 1.61). Examining predicted probabilities of STI, our findings show additive risks for women, black people and parental imprisonment.

Conclusion Adjusting for confounders, only paternal imprisonment is associated with slightly elevated risk of annual and lifetime risk of STI. Additive effects show that parental imprisonment modestly increases ethnic and female risk for STI.

\section{INTRODUCTION}

According to recent research, 2.6 million US children have a parent in jail or prison, with $4 \%$ of white, $24 \%$ of black, and $11 \%$ of
Strengths and limitations of this study

- This study addresses data and methodological issues of prior work to improve accuracy and reliability for estimating the association between parental imprisonment and risk of sexually transmitted infection (STI).

- The study leverages cross-sectional and longitudinal measures to compare lifetime and longitudinal risk.

- Comparative analysis is performed to determine potential variations in STI risk by maternal and paternal imprisonment, and respondent sex and ethnicity.

- The study lacks measures to determine underlying potential causal factors, such as residential instability and parental criminality that may explain the association.

- While STI self-reports are prospectively collected, data on parental imprisonment are retrospectively collected.

Hispanic children ever experiencing a parent serving time in state or federal prison. ${ }^{12}$ Parental imprisonment is an adverse childhood experience linked to a range of adversities from birth to death, including prenatal exposure to alcohol and drugs, poor academic and educational outcomes, criminal behaviour and subsequent imprisonment. ${ }^{3-6}$ In the last decade, research has increasingly linked parental imprisonment to health issues that include sexually transmitted infections (STIs), depression, cardiovascular and metabolic diseases, respiratory conditions, and infant and adult mortality. ${ }^{7-11}$ Due to the inter-relationship between parental imprisonment and other childhood traumas, such as family instability and child abuse, and linkage with outcomes, such as antisocial and risky behaviours, documenting associations and potential mediating effects is critical for linking parental imprisonment to health 
outcomes later in the life course. ${ }^{12-15}$ The present study assesses whether parental imprisonment is a risk factor for STIs and potential mediating factors that may explain this association.

The potential association between parental imprisonment and STIs in the USA is important given the scale of parental imprisonment in the USA, increasing rates of STI and resulting health complications from STI. Rates of STI have generally increased in the USA. Between 2000 and 2017, chlamydial infection rates doubled from 251.4 to 528.8 per 100000 , while gonorrhoea infection rates increased by $75 \%$ from 99.1 to 171.9 cases per 100000 between 2009 and 2017. ${ }^{16}$ An STI that is undetected and left untreated may result in a range of chronic health issues such as infertility or adverse birth outcomes (chlamydia, gonorrhoea), cervical and testicular cancers (human papillomavirus (HPV)), and mortality (syphilis, HIV/AIDS) ${ }^{16-18}$ An increased risk of STIs associated with experiencing parental imprisonment may thus contribute to a range of adverse outcomes later in the life course.

In cross-sectional analyses of the National Longitudinal Study of Adolescent to Adult Health (Add Health), parental imprisonment has been associated with STI in adolescence and adulthood. ${ }^{3151920}$ Further studies have linked STI with substance abuse, childhood trauma, early sexual activity and risky sexual behaviour. ${ }^{31519-23}$ These analyses also suggest that women ${ }^{19}$ and minorities ${ }^{2022}$ who experience parental imprisonment may be at greater likelihood of having an STI, though these sex and racial differentials were not tested for statistical significance. Parental imprisonment has also been associated with altered age trajectories for engaging in delinquent behaviour and drug use, and age trajectories may similarly vary for STI. ${ }^{24}$ Some research examining cross-sectional risk of STI at multiple time points suggests that STI risk associated with parental imprisonment may vary by life stage and be mediated by factors such as child abuse, family instability, substance use, adolescent antisocial behaviour (particularly, life course persistent or chronic offending) or sexual risk taking. ${ }^{19} 2026$

While this research suggests parental imprisonment is associated with STI, important research gaps remain that we address in our analysis. Extending prior research to incorporate longitudinal analysis is important for determining how the association between parental imprisonment and STI risk may hold or change as individuals age out of early adulthood, while addressing potential temporal ordering issues of co-occurring risks such as antisocial behaviour and substance use. ${ }^{2728}$ By comparing cross-sectional results for lifetime risk of STI at ages 24-32 years with longitudinal risk of annual STI, we are able to establish how parental imprisonment impacts age-graded risk of STI.

We also examine how the association between parental imprisonment and STI may vary by the potential confounding or mediating roles of other related factors. Understanding these mediation patterns is critical for identifying potential pathways between childhood adversity and later adverse outcomes associated with parental imprisonment that may impact STI risk. We examine if sex of parent and child differentiates risk, along with mediating patterns for four sets of factors: (1) demographic, (2) familial and neighbourhood characteristics (including familial socioeconomic status (SES) and household composition), (3) individual risk and resiliency, and (4) sexual risk factors.

We examine potential STI risk disparities for parental imprisonment by parent/child sex and ethnicity, ${ }^{7}$ particularly in light of findings that women and African Americans are more likely to contract an STI. ${ }^{29-31}$ Results by Khan $e t a t^{20}$ are suggestive that STI risk associated with parental imprisonment is higher for minority groups, but this study did not test if risk for parental imprisonment differed across ethnic groups. Furthermore, the compounded risks by sex and ethnicity may not be additive, leading to variation in STI risk associated with parental imprisonment (eg, black male and female respondents may have similar STI risk, or black women may have a greater STI risk than black men). By testing these associations, we are able to determine if the risk of parental imprisonment for STI may vary based on a respondent's sex and ethnicity.

To date, studies have separately tested for associations between parental imprisonment and diagnosis of (1) HIV/AIDS, (2) gonorrhoea and chlamydia, or (3) trichomoniasis, gonorrhoea and chlamydia. ${ }^{315} 19$ In contrast, examining parental imprisonment and a broader, general risk for being diagnosed with an STI provides insights into general STI risks linked with parental imprisonment. We estimate the general risk of STI associated with parental imprisonment in cross-sectional and longitudinal models.

Our analysis examines the validity of the models we estimate, addressing issues concerning survey weighting, small cell sizes, and missing data which may increase uncertainty and reliability issues in prior research on this topic. This is critical for providing consistent and reliable estimates gauging the extent to which parental imprisonment may be a risk factor for STI.

\section{METHODS \\ Data}

We use data from the US Add Health. The Add Health study initially surveyed approximately 90000 students enrolled in grades 7-12 (ages 12-18) in 1994-1995 in in-school interviews. Our study follows a subpopulation of $\sim 20750$ respondents who were randomly selected from the in-school sample for in-home interviews. These respondents were followed up at three later waves: $\sim 14700$ respondents at wave 2 in 1996, 15200 respondents at wave 3 in 2001-2002, and $\sim 15700$ respondents at wave 4 in 2007-2008. Of the original sample, the proportions of wave 1 respondents completing surveys at each round are: $71 \%$ at wave $2,73 \%$ at wave 3 and $75 \%$ at wave $4 .{ }^{32}$ Our analysis includes only individuals completing both wave 1 and wave 4 interviews, with $74.5 \%$ and $81.5 \%$ of 
these respondents completing interviews, respectively, at waves 2 and 3 .

Details of the survey design and reasons for nonresponse at each wave are available from the Add Health website (https://www.cpc.unc.edu/projects/addhealth).

Our analytical sample consists of 15684 individuals who completed questionnaires at both waves 1 and 4 when questions about biological mother and father imprisonment were first asked, including 14796 individuals with valid survey weights. The reduced number of cases arises from individuals' missing information from the school or household level needed to create nationally representative weights for the cohort; as an example, sibling pairs in the in-home sample but not enrolled in the same school were not given sampling weights. ${ }^{33}$

\section{Measures}

All measures are constructed using items taken from waves 1 to 4 of the Add Health survey and can be downloaded from the Add Health website. ${ }^{34}$

\section{Sexually transmitted infections}

Our outcome measure of STI is a dichotomous indicator for respondents reporting being told by a doctor or other health professionals of being infected with any of the following STIs: (1) chlamydia, (2) gonorrhoea, (3) trichomoniasis, (4) syphilis, (5) hepatitis B, (6) HPV, (7) HIV/AIDs and (8) other sexually transmitted diseases, not elsewhere reported by respondents such as genital herpes, genital warts, vaginitis, urethritis, pelvic inflammatory disease or cervicitis.

From these reports, we construct an indicator for (1) ever being infected with an STI and (2) being infected with an STI in the 12 months prior to interview (available at waves 3 and 4). For lifetime infection, we supplement wave 4 reports with reports of being infected with any of the STIs listed above at earlier waves, addressing cases where respondents are known to deny STIs in self-reports at older ages. ${ }^{35}$

\section{Parental imprisonment}

At wave 4, respondents were asked '(Has/did) your biological mother/father ever (spent/spend) time in jail or prison?' and 'How old were you when your biological mother/father went to jail or prison (the first time)?' Using these questions, we construct indicator variables for maternal and paternal imprisonment occurring prior to age 18 years. We code separate measures for (1) father imprisonment, (2) mother imprisonment, and (3) mutually exclusive categories of mother and/or father imprisonment. While prior research suggests recollection of childhood traumas and reporting of parental imprisonment yields reliable estimates, ${ }^{36} 37$ recollection of the specific age at first parent imprisonment may be less reliable, particularly in early childhood. Our coding addresses this potential issue in prior research.

\section{Demographic controls}

We include respondent age at each wave, biological sex, and if the respondent identified as black, white, Hispanic, Native American, Asian or other racial classification at wave 1 .

\section{Familial/neighbourhood controls}

We control for parent's reported level of education and family structure at wave 1 (in over $90 \%$ of cases, the parent reporting education is the biological mother or stepmother). We include wave 1 neighbourhood SES as the proportion of families in the respondent's census tract residing below the poverty level.

\section{Individual risk measures}

For individual controls, we incorporate measures of measured body mass index $\left(\mathrm{kg} / \mathrm{m}^{2}\right)$ at wave 2 , an indicator for physical child abuse (wave 4 self-report), difficult child temperament (wave 1 parent interview), a wave 1 school attachment scale, adolescent marijuana usage in the 30 days prior to the interview (wave 1 ), binge drinking in the prior 12 months to the interview (waves 2, 3 and 4), and a 12-item wave 1 delinquency score (details of the school attachment and delinquency scales are available in Guo et $a \hat{l}^{88}$ ).

\section{STI risk factors}

Measures include the total number of sexual partners before age 18 years and parental reports of the degree to which they discuss STI risk with respondents on a 5-point Likert scale (with higher scores indicating greater discussion about STI risks).

\section{Patient and public involvement}

This study uses anonymised secondary data from the Add Health. As a result, this study is conducted without patient involvement in designing the study, creating outcomes or interpreting results. Study participants are also not included in contributing to the writing or editing of this document for readability or accuracy.

\section{Analytical strategy}

To analyse the risk of lifetime STI, we use logistic regression. Add Health uses multiplicative weights ranging between 20 and 18342 (mean 1480.28, SD 1425.65) to create a representative national cohort at wave $4 .{ }^{34}$ This is a potential issue in prior studies where missing data and small cell counts used in analysis may substantially increase uncertainty. Analysis of unweighted data and controls to address sample bias may, alternatively, more efficiently estimate STI risk. ${ }^{39}$ We focus our presentation on the unweighted results, but also compare coefficients between the weighted and unweighted data to examine potential uncertainty. ${ }^{40}$

To analyse the probability of STI over time, we use a two-level random effects logistic regression model where self-reports of STI in the prior 12 months at each wave are nested within individuals. 
We impute 75 datasets using multiple imputation (MI) by chained equations to address missing data issues; we note imputation may address bias arising in prior research due to (1) missing data removing cases of greater social disadvantage where the effects of parental imprisonment have been found to be less significant, and (2) removing $12 \%$ of cases of mothers (78 of 643 ) and $20 \%$ of cases of fathers (458 of 2283) where respondents report their parent as having been imprisoned, but not reporting the exact age when their parent was first imprisoned. ${ }^{7442}$

Predicted probabilities and 95\% CIs are generated by estimating means and SEs using reported model estimates. These estimate results use baseline demographic controls for age, race/ethnicity and respondent sex to estimate variation among these groups, in the absence of mediators.

We use STATA V.15.1 for all analyses.

\section{RESULTS}

Table 1 contains descriptive statistics by respondent's history of parental imprisonment. Parental imprisonment is associated with increased risk of a range of adversities and disadvantages.

\section{Lifetime STI}

Table 2 presents results for lifetime risk of STI. The odds of STI were higher for imprisonment of the biological father (OR: $1.49,95 \%$ CI: 1.33 to 1.68 ) and biological mother (OR: $1.48,95 \%$ CI: 1.20 to 1.82 ) in the baseline demographic model (model 1). Modest declines in these estimates are associated with familial and neighbourhood factors (model 2), individual risk factors (model 3) and sexual behaviour risk factors (model 4). Biological father remains a risk factor for STI (OR: 1.24, 95\% CI: 1.04 to 1.48 ) with the inclusion of all controls, while the $95 \%$ CIs for the OR of maternal imprisonment included the null value of 1 (OR: 1.13, 95\% CI: 0.94 to 1.36 ).

Similar ORs for STI are observed for models for imprisonment of the biological father only (OR: 1.52, 95\% CI: 1.34 to 1.71 ), biological mother only (OR: $1.59,95 \% \mathrm{CI}$ : 1.20 to 2.10 ), and biological mother and father (OR: 1.58, $95 \%$ CI: 1.16 to 2.15$)$. Similar mediation patterns are observed for biological father and biological mother imprisonment, with 95\% CIs showing ORs $>1$ for biological father only (models 1-5), biological mothers only (models 1-4), and both father and mother imprisonment (models 1-4).

In all cases, no single set of risk factors results in nonsignificance. Online supplemental table S1 contains the ORs and 95\% CIs for parental imprisonment and controls for results from model 5 in table 2. Results using survey weights (online supplemental table S2) also show comparable ORs with those presented in table 2, with wider CIs.

We find no significant interactions for parental imprisonment with respondent's sex and race. To examine cumulative risk, we estimate joint probabilities for lifetime STI by child biological sex, black/non-black ethnicity, and mother or father imprisonment, presented in table 3. These results show that being female, having an incarcerated parent and being black have additive effects for ever being infected with an STI. For example, a nonblack man with no history of paternal imprisonment has a predicted probability of infection of $8.9 \%$ (95\% CI: $8.2 \%$ to $9.6 \%$ ), while those with a history of paternal imprisonment have a predicted probability of $12.5 \%$ (95\% CI: $11.2 \%$ to $13.9 \%$ ). In contrast, black women reporting no history of parental imprisonment had a $52.4 \%$ (95\% CI: $50.2 \%$ to $54.6 \%$ ) predicted probability of STI, compared with $61.7 \%$ (95\% CI: $58.8 \%$ to $64.7 \%$ ) with a history of paternal imprisonment. Similar predicted probabilities are associated with maternal imprisonment.

\section{Longitudinal risk of STI}

Table 4 examines longitudinal odds of STI in the 12 months prior to the interview. In these models, father imprisonment in the baseline model is associated with higher odds of STI (OR: 1.33, 95\% CI: 1.13 to 1.56). This association shows slight mediation when controls were introduced for familial and neighbourhood (model 2), individual (model 3) and sexual behaviour factors (model 4); however, the $95 \%$ CIs for paternal imprisonment include the null value of 1 (95\% CI: 0.98 to 1.37) when all controls were included (model 5). Maternal imprisonment shows no association with 12-month STI risk (model $595 \%$ CI: 0.75 to 1.40 ). In comparing imprisonment risk for categories of father and/or mother imprisonment, the 95\% CIs of the association for father-only imprisonment and STI risk remain $>1$ across all models, but mother-only imprisonment, and father and mother imprisonment show no associations with STI risk.

Online supplemental table S3 contains the ORs and 95\% CIs for parental imprisonment and controls for results from model 5 in table 4 . We note that respondent age and heavy-drinking measures are time-varying measures that are not directly comparable with results presented in online supplemental table S1.

To test for differences in father imprisonment and 12-month STI risk, we examine if respondent age, ethnicity and sex moderated results for paternal imprisonment, with no statistically significant moderation patterns observed. In lieu of moderation, we examine if predicted probabilities of STI diagnosis by age, ethnicity and respondent sex show additive effects, as illustrated by figure 1 (non-black respondents) and figure 2 (black respondents). In all models, there is a higher probability of diagnosis through the mid-20s, before the probability of STI diagnosis stabilises. In figure 1, the predicted probability of diagnosis of an STI in the past 12 months is higher for women than men, with parental imprisonment being associated with a modest increase in risk. Figure 2 shows a similar pattern, with higher baseline rates among black respondents. Collectively, these figures illustrate additive effects for paternal imprisonment, being black and being a woman, with nearly one-fifth of black women 
Table 1 Means, SDs and test of group means for individual, family, neighbourhood and sexual risk variables, by exposure to parental imprisonment in childhood (National Longitudinal Study of Adolescent to Adult Health, 1994-2008)

Test of

Parental imprisonment No parental imprisonment group (n=2339)

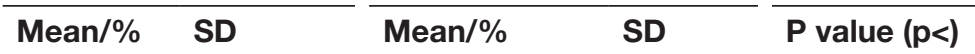

\section{Parent imprisonment}

Sex of parent

$\begin{array}{lr}\text { Father imprisoned } & 87.16 \\ \text { Mother imprisoned } & 21.23 \\ \text { Joint parental imprisonment } & 78.77 \\ \text { Father only imprisoned } & 12.84 \\ \text { Mather only imprisoned } & 8.39 \\ \text { Mother and father both imprisoned } & 31.53 \\ \text { Ever STI diagnosis } & \end{array}$

STI diagnosis, prior 12 months

$\begin{array}{lllll}\text { Wave } 3 & 7.77 & 5.39 & 0.0001 \\ \text { Wave } 4 & 9.71 & 7.06 & 0.0001\end{array}$

\section{Demographic measures}

Age at interview (years)

\begin{tabular}{|c|c|c|c|c|c|}
\hline Wave 1 & 15.41 & 1.70 & 15.63 & 1.74 & 0.0001 \\
\hline Wave 3 & 21.76 & 1.74 & 21.95 & 1.77 & 0.0001 \\
\hline Wave 4 & 28.32 & 1.75 & 28.52 & 1.79 & 0.0001 \\
\hline Male & 44.91 & & 47.08 & & 0.0500 \\
\hline Female & 55.09 & & 52.92 & & 0.0500 \\
\hline White & 46.38 & & 54.00 & & 0.0001 \\
\hline Black & 31.69 & & 20.74 & & 0.0001 \\
\hline Hispanic & 16.53 & & 15.87 & & 0.4387 \\
\hline Asian & 1.76 & & 6.91 & & 0.0001 \\
\hline Native American & 2.83 & & 1.55 & & 0.0001 \\
\hline \multicolumn{6}{|l|}{ Family structure (wave 1) } \\
\hline Two biological parents & 21.96 & & 57.82 & & 0.0001 \\
\hline Single mother & 36.09 & & 21.23 & & 0.0001 \\
\hline Single father & 4.62 & & 3.10 & & 0.0002 \\
\hline Two parent, one biological & 25.09 & & 12.92 & & 0.0001 \\
\hline Other family structure & 12.24 & & 4.92 & & 0.0001 \\
\hline \multicolumn{6}{|l|}{ Completed parental education } \\
\hline Bachelor's degree & 15.34 & & 25.61 & & 0.0001 \\
\hline High school & 60.52 & & 57.96 & & 0.0183 \\
\hline
\end{tabular}




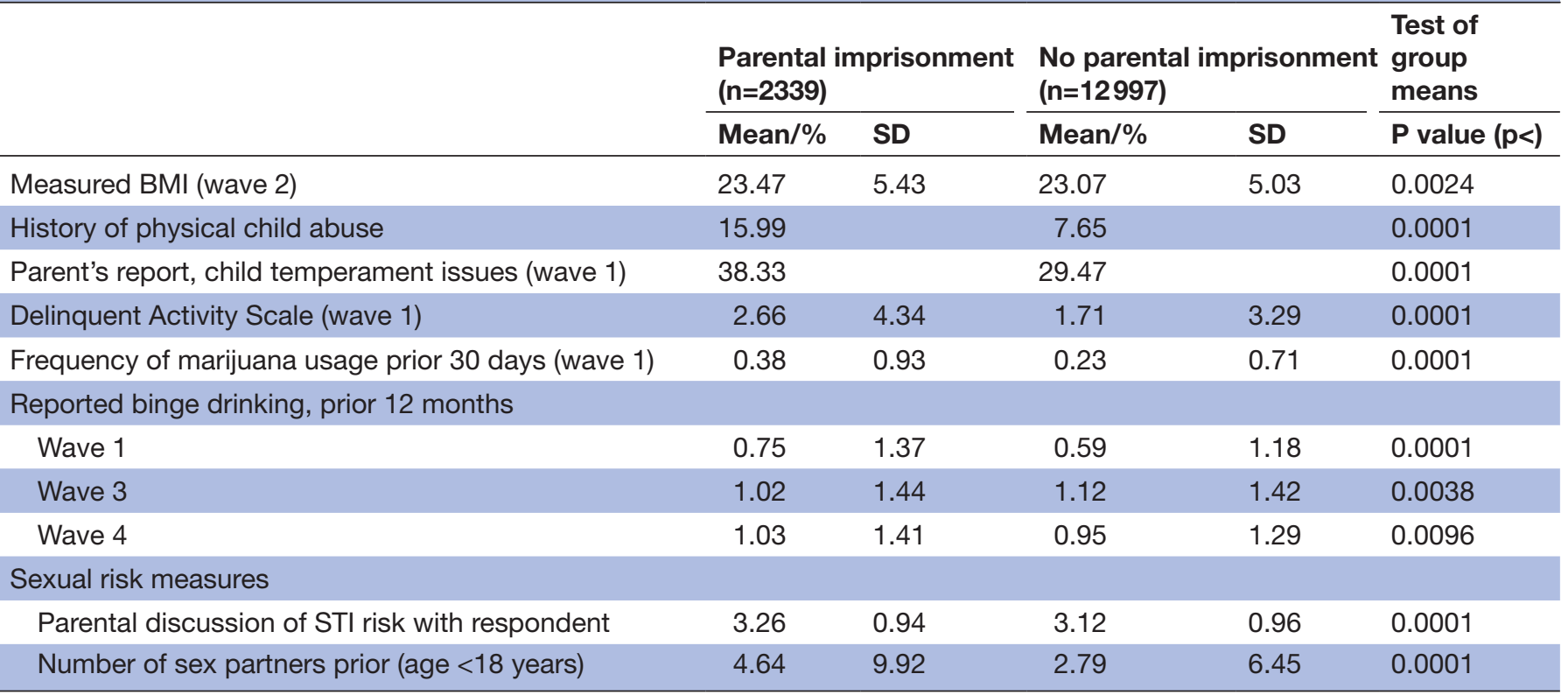

BMI, body mass index; STI, sexually transmitted infection.

who experience paternal imprisonment being diagnosed with an STI in the 12 months prior to interviews.

\section{Sensitivity analysis}

We conduct supplemental analyses to (1) compare MI results with complete case analysis for the main findings (online supplemental tables S4 and S5); (2) compare the findings by Le $e t a l^{15}$ for laboratory-confirmed infections of chlamydia and gonorrhoea with our analysis for respondent self-reports of lifetime chlamydia and/or gonorrhoea infection (online supplemental table S6); and (3) test moderation results using complete case analysis by examining interactions for parental imprisonment by biological sex, race/ethnicity, and age in longitudinal models (raw output for moderation testing available on request). Comparisons (1) and (3) yield substantively similar results. For (2), our results are consistent with prior research on variations between lab-confirmed and self-reported STI for: (1) father only, and (2) mother and

Table 2 ORs and 95\% Cls for lifetime STI diagnosis among adults aged 26-32 years reporting parental imprisonment in childhood (National Longitudinal Study of Adolescent to Adult Health, 1994-2008)

\begin{tabular}{|c|c|c|c|c|c|}
\hline & $\begin{array}{l}\text { Model 1: } \\
\text { demographic }\end{array}$ & $\begin{array}{l}\text { Model 2: } \\
\text { family and } \\
\text { neighbourhood }\end{array}$ & $\begin{array}{l}\text { Model 3: } \\
\text { individual risk }\end{array}$ & $\begin{array}{l}\text { Model 4: sexual } \\
\text { risk }\end{array}$ & $\begin{array}{l}\text { Model 5: full } \\
\text { controls }\end{array}$ \\
\hline $\begin{array}{l}\text { Biological father } \\
\text { imprisonment }\end{array}$ & 1.49 (1.33 to 1.68$)$ & 1.36 (1.21 to 1.54$)$ & 1.33 (1.19 to 1.49$)$ & 1.38 (1.23 to 1.55$)$ & 1.24 (1.04 to 1.48$)$ \\
\hline $\begin{array}{l}\text { Biological mother } \\
\text { imprisonment }\end{array}$ & 1.48 (1.20 to 1.82$)$ & $1.22(1.02$ to 1.44$)$ & 1.30 (1.09 to 1.55$)$ & 1.37 (1.16 to 1.63$)$ & $1.13(0.94$ to 1.36$)$ \\
\hline $\begin{array}{l}\text { Biological mother-only } \\
\text { imprisonment }\end{array}$ & 1.59 (1.20 to 2.10$)$ & $1.32(1.00$ to 1.75$)$ & 1.39 (1.05 to 1.87$)$ & $1.47(1.11$ to 1.95$)$ & $1.20(0.90$ to 1.61$)$ \\
\hline $\begin{array}{l}\text { Biological mother and } \\
\text { father imprisonment }\end{array}$ & 1.58 (1.16 to 2.15$)$ & 1.33 (1.07 to 1.66$)$ & 1.39 (1.11 to 1.72$)$ & 1.45 (1.07 to 1.99$)$ & 1.21 (0.97 to 1.52$)$ \\
\hline
\end{tabular}

Results are presented for parental imprisonment (age $<18$ years) for (1) any reported biological father imprisonment, (2) any report of biological mother imprisonment, and (3) combined reports of biological father and mother imprisonment. Model 1 (demographic controls)=parental Imprisonment+respondent age+respondent ethnicity+respondentsex. Model 2 (family and neighbourhood controls)=model $1+$ wave 1 family structure+parent educational attainment+census tract family poverty rate. Model 3 (individual risk controls)=model 1+respondent BMI+adolescent school attachment+childhood physical abuse+difficult child temperament+adolescent marijuana use+adolescent binge drinking+serious adolescent delinquency. Model 4 (sexual risk controls)=model 1+parental discussion of STI risk+number of sex partners prior to age 18 years. Model 5 (full controls)=all variables used in prior models.

BMI, body mass index; STI, sexually transmitted infection. 
Table 3 Predicted probabilities and 95\% Cls for ever being infected with an STI, by parent sex, child sex, and black/nonblack racial classification (National Longitudinal Study of Adolescent to Adult Health, 1994-2008)

\begin{tabular}{lllll} 
& Non-black, male & Non-black, female & Black, male & Black, female \\
\hline $\begin{array}{l}\text { Biological father } \\
\text { imprisonment }\end{array}$ & $12.5 \%(11.2 \%$ to $13.9 \%)$ & $29.3 \%(27.0 \%$ to $31.7 \%)$ & $35.8 \%(32.7 \%$ to $38.8 \%)$ & $61.7 \%(58.8 \%$ to $64.7 \%)$ \\
$\begin{array}{l}\text { No biological father } \\
\text { imprisonment }\end{array}$ & $8.9 \%(8.2 \%$ to $9.6 \%)$ & $22.1 \%(21.1 \%$ to $23.2 \%)$ & $27.6 \%(25.6 \%$ to $29.5 \%)$ & $52.4 \%(50.2 \%$ to $54.6 \%)$ \\
$\begin{array}{l}\text { Biological mother } \\
\text { imprisonment }\end{array}$ & $13.5 \%(11.0 \%$ to $16.0 \%)$ & $30.4 \%(25.6 \%$ to $35.1 \%)$ & $37.7 \%(32.7 \%$ to $42.7 \%)$ & $63.2 \%(58.4 \%$ to $68.0 \%)$ \\
$\begin{array}{l}\text { No biological mother } \\
\text { imprisonment }\end{array}$ & $9.6 \%(8.9 \%$ to $10.0 \%)$ & $23.0 \%(22.0 \%$ to $24.1 \%)$ & $29.1 \%(27.1 \%$ to $31.0 \%)$ & $53.7 \%(51.7 \%$ to $55.8 \%)$ \\
\hline
\end{tabular}

Predicted probabilities generated based on model 1 of table 2 for respondents reporting if their (1) biological father or (2) biological mother was imprisoned at age $<18$ years. Model predictors of STI include parental imprisonment, respondent age, respondent sex and respondent ethnicity.

STI, sexually transmitted infection.

father imprisonment are lower, but within $95 \%$ CIs, while odds for mother-only imprisonment are lower than the results reported by Le $e t a l^{15}$

\section{DISCUSSION}

Using a US-based cohort study, we demonstrate that individuals experiencing paternal imprisonment, without co-occurring maternal imprisonment, in childhood is an independent risk factor for (1) higher lifetime odds of STI and (2) longitudinal annual STI risk in adults aged 18-32 years. In basic demographic models controlling for age, race and biological sex, we find maternal and/or paternal imprisonment is associated with increased cumulative risk of STI, with predicted probabilities for STI showing additive risk for parental imprisonment, respondent sex and race. However, after introducing controls, only paternal imprisonment (without co-occurring maternal imprisonment) remains significant. In longitudinal models, respondents experiencing paternal imprisonment only in childhood face a statistically higher risk for annual STI after controls are added. Respondent sex and ethnicity also independently raise risks of annual infection in longitudinal analysis. Furthermore, ORs for lifetime and annual STIs associated with experiencing paternal imprisonment only are statistically significant and similar $(\mathrm{OR} \sim 1.2)$ once adjusted for controls, suggesting consistency in crosssectional and longitudinal results for paternal imprisonment only as a modest, but independent risk factor for STI.

Table 4 ORs and 95\% Cls for longitudinal risk of STI in the 12 months prior to interview, ages 18-32 (National Longitudinal Study of Adolescent to Adult Health, 1994-2008)

\begin{tabular}{|c|c|c|c|c|c|}
\hline & $\begin{array}{l}\text { Model 1: } \\
\text { demographic }\end{array}$ & $\begin{array}{l}\text { Model 2: } \\
\text { family and } \\
\text { neighbourhood }\end{array}$ & $\begin{array}{l}\text { Model 3: } \\
\text { individual risk }\end{array}$ & $\begin{array}{l}\text { Model 4: sexual } \\
\text { risk }\end{array}$ & $\begin{array}{l}\text { Model 5: full } \\
\text { controls }\end{array}$ \\
\hline $\begin{array}{l}\text { Biological father } \\
\text { imprisonment }\end{array}$ & 1.33 (1.13 to 1.56$)$ & 1.26 (1.06 to 1.50$)$ & 1.22 (1.03 to 1.43$)$ & 1.26 (1.07 to 1.49$)$ & $1.15(0.98$ to 1.37$)$ \\
\hline $\begin{array}{l}\text { Biological mother } \\
\text { imprisonment }\end{array}$ & 1.22 (0.89 to 1.66$)$ & $1.10(0.81$ to 1.51$)$ & 1.09 (0.80 to 1.48$)$ & $1.17(0.85$ to 1.58$)$ & $1.02(0.75$ to 1.40$)$ \\
\hline $\begin{array}{l}\text { Biological mother-only } \\
\text { imprisonment }\end{array}$ & 1.43 (0.96 to 2.14$)$ & 1.33 (0.88 to 2.00$)$ & 1.31 (0.88 to 1.95$)$ & 1.37 (0.92 to 2.05$)$ & $1.24(0.81$ to 1.86$)$ \\
\hline $\begin{array}{l}\text { Biological mother and } \\
\text { father Imprisonment }\end{array}$ & 1.12 (0.69 to 1.82$)$ & 1.03 (0.63 to 1.70$)$ & 0.95 (0.58 to 1.56$)$ & 1.06 (0.65 to 1.74$)$ & 0.89 (0.54 to 1.46 \\
\hline
\end{tabular}




\section{Non-Black respondents}
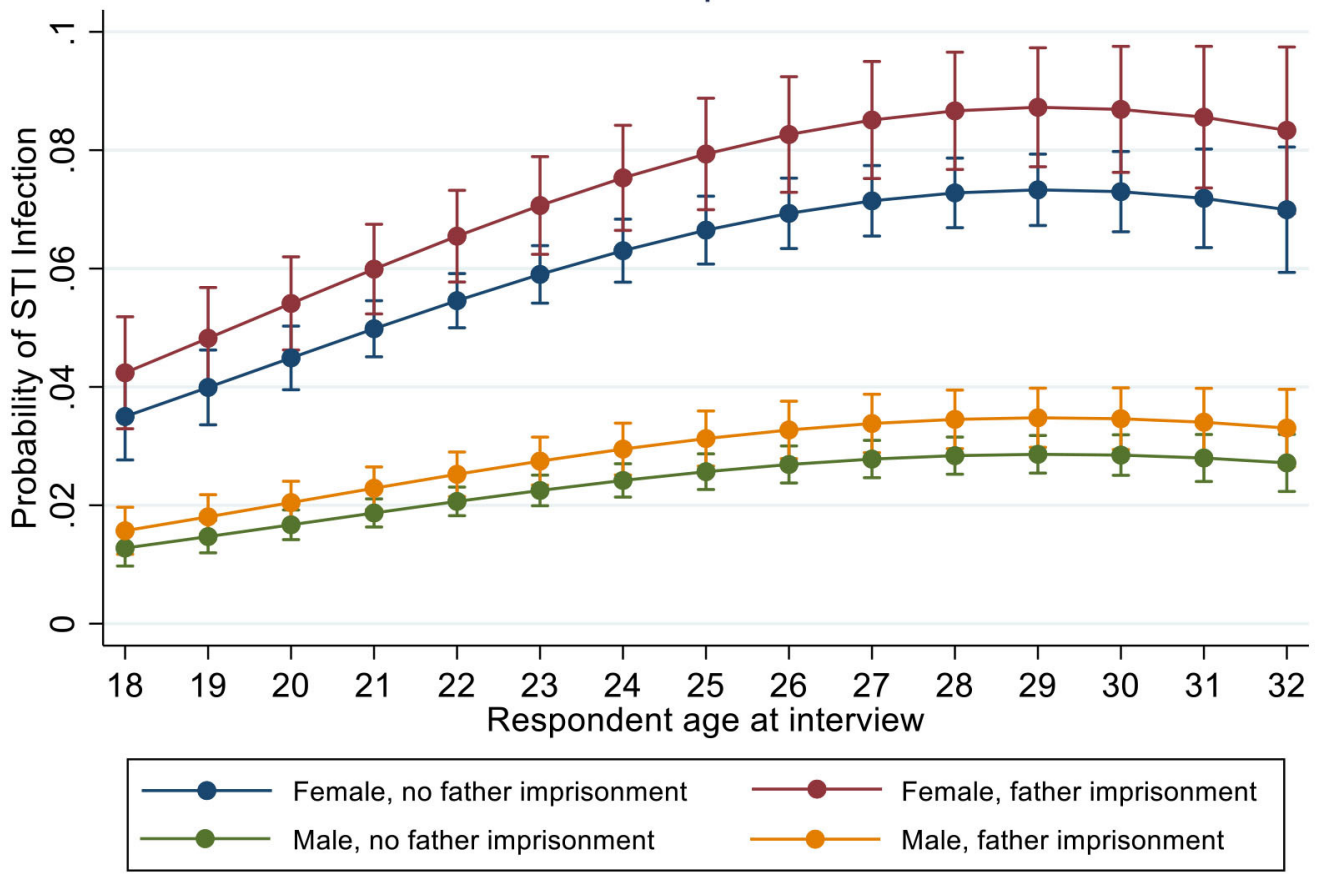

Figure 1 Age-graded risk for self-reported STI in 12 months prior to interview for non-black respondent infection probabilities are presented by respondent sex and father's history of imprisonment (National Longitudinal Study of Adolescent to Adult Health, 1994-2008). STI, sexually transmitted infection.

In examining mediation patterns, the introduction of familial/neighbourhood, individual risk and resilience factors, and sexual risk each show some mediation effect between (1) maternal and/or paternal imprisonment and lifetime STI and (2) paternal imprisonment and annual STI. While factors such as risky sexual behaviours
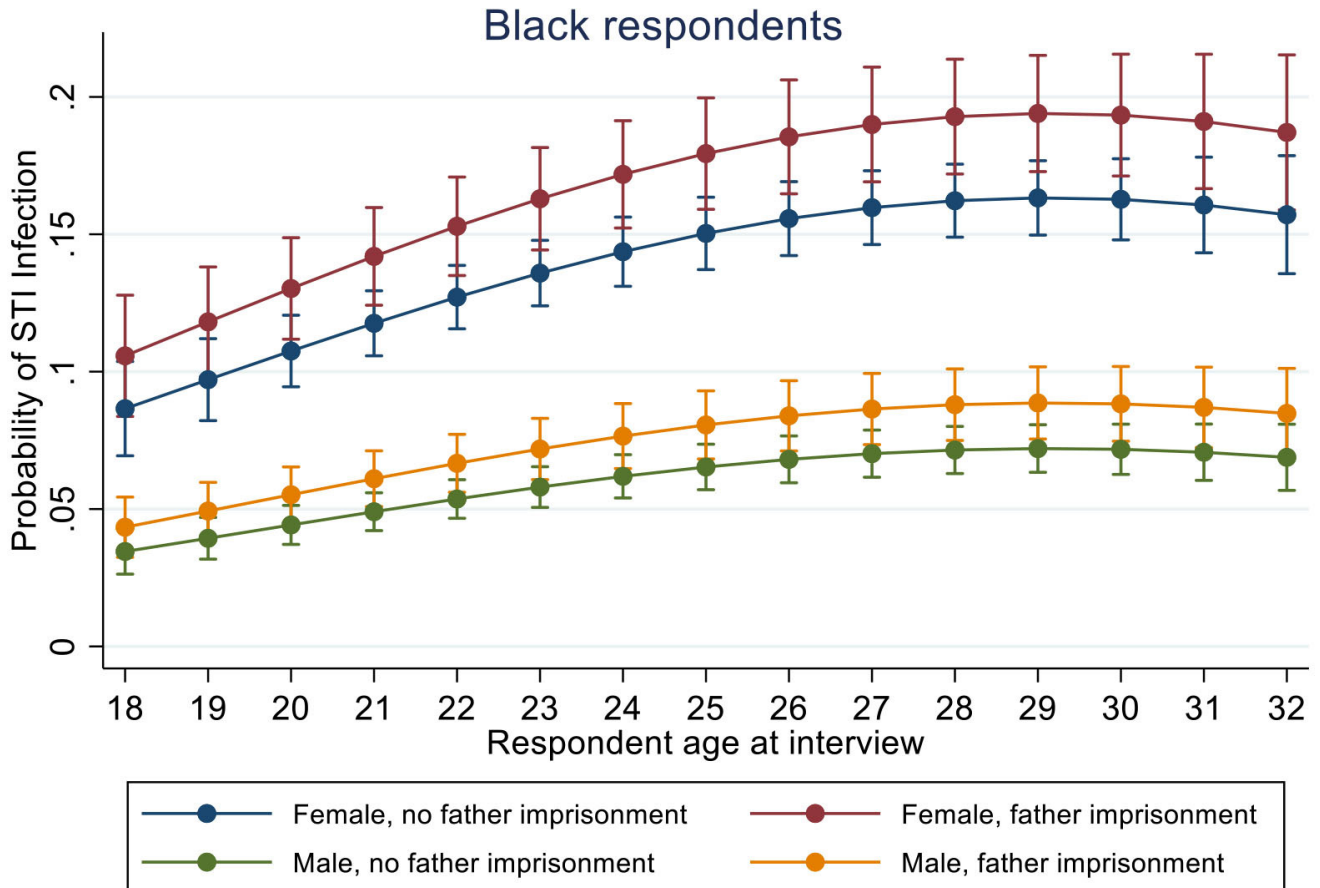

Figure 2 Age-graded risk for self-reported STI in 12 months prior to interview for black respondent infection probabilities are presented by respondent sex and father's history of imprisonment (National Longitudinal Study of Adolescent to Adult Health, 1994-2008). STI, sexually transmitted infection. 
and substance abuse may potentially mediate the relationship between parental imprisonment and STI, ${ }^{15} 20$ our results show that the set of combined controls fully or substantially mitigated these associations. This finding is generally consistent with other studies where results for parental imprisonment are partially or fully mediated when controls are added for co-occurring risks such as parental criminality, poverty and residential instability. ${ }^{12134344}$

As noted by Roettger and Dennison, ${ }^{5}$ complex interrelationships exist between parental imprisonment, adversities encountered throughout stages of the life course and inter-related adverse behavioural outcomes. Our findings align with this hypothesis, for instance, that paternal imprisonment shows similarly increased odds for STI that are also associated with child abuse and adolescent/adult substance use. While it remains critical that public health measures encourage safe sex and frequent testing to prevent and treat STIs associated with parental imprisonment, the need for earlier, more comprehensive health interventions is also important to address broader mental and physical health disparities linked with parental imprisonment and mass incarceration. ${ }^{45-47}$ For example, treatment for substance use disorders and mental health issues linked with childhood abuse may be important components for reducing risky sexual behaviours among individuals with co-occurring histories of parental imprisonment. Addressing these "packages of risk ${ }^{48}$-parental imprisonment and inter-related risks arising from different periods in the life course-is critical for ensuring that policies address the underlying causes which lead to risky sexual behaviours that may result in STI and later health complications.

One unexpected finding was that maternal imprisonment and joint mother and father imprisonment, after adjusting confounders and mediators, are not significant predictors of lifetime STI risk and are also non-significant in longitudinal analysis. While this may be due to smaller sample sizes compared with paternal imprisonment, it is also critical to note that these types of imprisonment may be associated with broader sets of disadvantages, such as poverty and family instability. ${ }^{48} 49$

\section{Strengths and weaknesses}

Our study contains a number of strengths. By combining cumulative and longitudinal analysis for STI, we investigate if the general association between parental imprisonment and STI consistently holds over time for a broad range of STIs. Addressing a range of prior methodological issues and using supplemental analysis to investigate the reliability and accuracy of our results, we examine the validity of the association between parental imprisonment and STI risk. Examining variations by age, biological sex and ethnicity of respondents using predicted probabilities, we test for potential variations in parental imprisonment and STI. By including a range of controls, we shed additional insight into potential adverse childhood experiences and co-occurring risk factors that may mediate the association between parental imprisonment and sexual behaviours that may lead to STI. Lastly, by examining STI over time and supplementing wave 4 STI reports of lifetime infection with reports of STI at earlier ages, we (1) control for recall bias ${ }^{35}$ and (2) allow for additional time for cases where asymptomatic STIs may be under-reported due to lack of testing at one particular timepoint, ${ }^{50}$ known sources of biases for self-reported measures.

Our study also contains notable limitations. Prior research shows Add Health self-reports of STIs are slightly lower overall for the general population, with greater under-reporting for minorities ${ }^{51}$; laboratorybased testing may thus yield, particularly longitudinally, variation from our reported findings of similar risks for parental imprisonment by ethnicity over time. As many STIs may be asymptomatic and revealed only with testing, our longitudinal analysis represents prevalence of 'diagnosis,' not infection rates. ${ }^{35} 52$ Due to variation in questions across waves, we are unable to examine longitudinal models in adolescence, or analyse changes in STI risk between adolescence and adulthood. Our measure of parental imprisonment is also based on recollection and may include shorter jail and longer prison sentences that yield differing risks; the collection of administrative data may provide more reliable data for evaluating STI risk within a jurisdiction. ${ }^{53}$ Data limitations, such as the lack of prospective data on parental imprisonment in childhood, the inability to temporally link parental imprisonment with subsequent sexual risk and STIs, and unmeasured, related factors such as exposure to family instability and parental criminality, also prevent us from exploring underlying causation. Gene-environment interactions for risky behaviours, such as self-control or sensation seeking, that lead to increased STI risk are not observed in our study but may also explain our association if transmitted from parent to child. ${ }^{54-56}$

\section{Conclusion}

This study provides evidence that childhood paternal imprisonment, without co-occurring maternal imprisonment, is associated with elevated lifetime and longitudinal annual risks of having an STI in early and mid-adulthood. We find that annual and lifetime risk of STI associated with paternal imprisonment only is additive to increased risks of STIs for women and black respondents. For adults who have experienced parental imprisonment in childhood, increased testing and treatment for STIs may help to reduce increased risks. However, broader policies and interventions are needed to address co-occurring childhood traumas and behavioural issues that link parental imprisonment with sexual health disparities.

Acknowledgements This research uses data from Add Health, a programme project directed by Kathleen Mullan Harris and designed by J Richard Udry, Peter S Bearman and Kathleen Mullan Harris at the University of North Carolina at Chapel Hill, and funded by grant P01-HD31921 from the Eunice Kennedy Shriver National Institute of Child Health and Human Development, with cooperative funding from 23 other federal agencies and foundations. Information on how to obtain the Add 
Health data files is available on the Add Health website (http://www.cpc.unc.edu/ addhealth). No direct support was received from grant P01-HD31921 for this analysis. Access to the Add Health data was made possible through the NIH/NICHD supported (2P2CHD066613) University of Colorado Population Center (CUPC).

Contributors Conception and design of the study-MR and BH. Data preparation and analysis-MR. Interpreting results-MR and BH. Drafting of the initial and revised manuscripts-MR. Revising all manuscripts submitted critically-MR and BH. All authors approved the final manuscript.

Funding The authors have not declared a specific grant for this research from any funding agency in the public, commercial or not-for-profit sectors.

Competing interests None declared.

Patient consent for publication Not required.

Ethics approval This project was reviewed and approved by The Australian National University Human Ethnics Research Committee (approval \#: 2018/283).

Provenance and peer review Not commissioned; externally peer reviewed.

Data availability statement Data may be obtained from a third party and are not publicly available. To maintain confidentiality of the data, data access is restricted by the study owners, the University of North Carolina at Chapel Hill. Access to the restricted data used in this paper may be obtained via contract by contacting the data owners via their website: https://www.cpc.unc.edu/projects/addhealth/ contracts.

Supplemental material This content has been supplied by the author(s). It has not been vetted by BMJ Publishing Group Limited (BMJ) and may not have been peer-reviewed. Any opinions or recommendations discussed are solely those of the author(s) and are not endorsed by BMJ. BMJ disclaims all liability and responsibility arising from any reliance placed on the content. Where the content includes any translated material, BMJ does not warrant the accuracy and reliability of the translations (including but not limited to local regulations, clinical guidelines, terminology, drug names and drug dosages), and is not responsible for any error and/or omissions arising from translation and adaptation or otherwise.

Open access This is an open access article distributed in accordance with the Creative Commons Attribution Non Commercial (CC BY-NC 4.0) license, which permits others to distribute, remix, adapt, build upon this work non-commercially, and license their derivative works on different terms, provided the original work is properly cited, appropriate credit is given, any changes made indicated, and the use is non-commercial. See: http://creativecommons.org/licenses/by-nc/4.0/.

\section{ORCID iDs}

Michael Roettger http://orcid.org/0000-0002-8253-5927

Brian Houle http://orcid.org/0000-0003-2157-3118

\section{REFERENCES}

1 Sykes BL, Pettit BMass incarceration, family complexity, and the reproduction of childhood disadvantage. Ann Am Acad Pol Soc Sci 2014;654:127-49.

2 Sykes BL, Pettit B. Measuring the exposure of parents and children to incarceration. In: Eddy JM, Poehlmann-Tynan J, eds. Handbook on children with incarcerated parents. New York: Springer, 2019.

3 Lee RD, Fang X, Luo F. The impact of parental incarceration on the physical and mental health of young adults. Pediatrics 2013;131:e1188-95.

4 Murray J, Bijleveld CC, Farrington DP, et al. Effects of parental incarceration on children: cross-national comparative studies. Washington, DC: American Psychological Association, 2014.

5 Roettger ME, Dennison S. Interrupting intergenerational offending in the context of America's social disaster of mass imprisonment. Am Behav Sci 2018;62:1545-61.

6 Finkelhor D, Shattuck A, Turner $\mathrm{H}$, et al. A revised inventory of adverse childhood experiences. Child Abuse Negl 2015;48:13-21.

7 Wildeman C, Goldman AW, Turney K. Parental incarceration and child health in the United States. Epidemiol Rev 2018;40:146-56.

8 van de Weijer SGA, Smallbone HS, Bouwman V. Parental imprisonment and premature mortality in adulthood. J Dev Life Course Criminol 2018;4:148-61.

9 Turney K. Stress proliferation across generations? Examining the relationship between parental incarceration and childhood health. $J$ Health Soc Behav 2014;55:302-19.

10 Wildeman $\mathrm{C}$, Andersen $\mathrm{SH}$, Lee $\mathrm{H}$, et al. Parental incarceration and child mortality in Denmark. Am J Public Health 2014;104:428-33.
11 Wildeman C. Imprisonment and infant mortality. Social Problems 2012;59:228-57.

12 WILDEMAN C, ANDERSEN SH. Paternal incarceration and children's risk of being charged by early adulthood: Evidence from a danish policy shock. Criminology 2017;55:32-58.

13 MURRAY J, LOEBER R, PARDINI D. Parental involvement in the criminal justice system and the development of youth theft, marijuana use, depression, and poor academic performance. Criminology 2012;50:255-302.

14 Giordano PC. Legacies of crime: a follow-up of the children of highly delinquent girls and boys. Cambridge University Press, 2010.

15 Le GT, Deardorff J, Lahiff M. Intergenerational associations between parental incarceration and children's sexual risk taking in young adulthood. J Adolescent Health 2019;64:398-404. doi:10.1016/j. jadohealth.2018.09.028

16 Centers for Disease Control and Prevention. Sexually transmitted disease surveillance 2017. Atlanta, GA: Centers for Disease Control and Prevention, 2018.

17 Johnson HL, Ghanem KG, Zenilman JM, et al. Sexually transmitted infections and adverse pregnancy outcomes among women attending inner city public sexually transmitted diseases clinics. Sex Transm Dis 2011;38:167-71.

18 American College of Obstetricians and Gynecologists. Frequently asked questions FAQ 133 pregnancy, 2017.

19 London S, Quinn K, Scheidell JD, et al. Adverse experiences in childhood and sexually transmitted infection risk from adolescence into adulthood. Sex Transm Dis 2017;44:524-32.

20 Khan MR, Scheidell JD, Rosen DL, et al. Early age at childhood parental incarceration and STI/HIV-related drug use and sex risk across the young adult lifecourse in the US: heightened vulnerability of black and Hispanic youth. Drug Alcohol Depend 2018;183:231-9.

21 Turney K, Goldberg RE. Paternal incarceration and early sexual onset among adolescents. Popul Res Policy Rev 2019;38:95-123.

22 Nebbitt VE, Voisin DR, Tirmazi MT. Early onset of sexual intercourse and parental incarceration among African American youth living in urban public housing. J Urban Health 2017;94:125-35.

23 Heard-Garris N, Winkelman TNA, Choi H, et al. Health care use and health behaviors among young adults with history of parental incarceration. Pediatrics 2018;142:e20174314.

24 Roettger ME, Swisher RR, Kuhl DC, et al. Paternal incarceration and trajectories of marijuana and other illegal drug use from adolescence into young adulthood: evidence from longitudinal panels of males and females in the United States. Addiction 2011;106:121-32.

25 Roettger ME, Swisher RR. Associations of fathers'history of incarceration with sons'delinquency and arrest among black, white, and Hispanic males in the United States. Criminology 2011;49:1109-47.

26 Parkes A, Waylen A, Sayal K, et al. Which behavioral, emotional and school problems in middle-childhood predict early sexual behavior? $J$ Youth Adolesc 2014;43:507-27.

27 Sabin CA, Phillips AN. Cohort studies in sexual health. Sex Transm Infect 2001;77:174-8.

28 Allison PD. Fixed effects regression methods for longitudinal data using SAS. Cary, NC: Sas Institute, 2014.

29 Wildsmith E, Schelar E, Peterson K, et al. Sexually transmitted diseases among young adults: prevalence, perceived risk, and risktaking behaviors. Child Trends Research Brief 2010;10:1-8.

30 Upchurch DM, Mason WM, Kusunoki Y, et al. Social and behavioral determinants of self-reported STD among adolescents. Perspect Sex Reprod Health 2004;36:276-87.

31 Paul C, van Roode T, Herbison P, et al. Longitudinal study of selfreported sexually transmitted infection incidence by gender and age up to age thirty-two years. Sex Transm Dis 2009;36:63-9.

32 Harris KM, Halpern CT, Whitsel EA, et al. Cohort profile: the National longitudinal study of adolescent to adult health (add health). Int J Epidemiol 2019;48:1415

33 Chantala K. Constructing weights to use in analyzing pairs of individuals from add health data, 2001. Available: https://addhealth. cpc.unc.edu/wp-content/uploads/docs/user_guides/pweights.pdf [Accessed 3 Sep 2020].

34 Harris KM, Halpern CT, Whitsel EA. The National longitudinal study of adolescent to adult health: codebooks for restricted-use data, 2009. Available: https://addhealth.cpc.unc.edu/documentation/codebooks/

35 Dariotis JK, Pleck JH, Sonenstein FL, et al. What are the consequences of relying upon self-reports of sexually transmitted diseases? lessons learned about recanting in a longitudinal study. J Adolesc Health 2009;45:187-92.

36 Foster $\mathrm{H}$, Hagan J. Maternal and paternal imprisonment in the stress process. Soc Sci Res 2013;42:650-69.

37 Winegar RK, Lipschitz DS. Agreement between hospitalized adolescents' self-reports of maltreatment and witnessed home 
violence and clinician reports and medical records. Compr Psychiatry 1999:40:347-52.

38 Guo G, Roettger ME, Cai T. The integration of genetic propensities into social-control models of delinquency and violence among male youths. Am Sociol Rev 2008;73:543-68.

39 Cameron AC, Trivedi PK. Microeconometrics: methods and applications. Cambridge, UK: Cambridge university press, 2005.

40 Bollen KA, Biemer PP, Karr AF, et al. Are survey weights needed? A review of diagnostic tests in regression analysis. Annu Rev Stat Appl 2016;3:375-92.

41 Graham JW. Missing data: analysis and design. Berlin: Springer Science \& Business Media, 2012.

42 Royston P, White IR. Multiple imputation by chained equations (MICE): implementation in Stata. J Stat Softw 2011;45:1-20.

43 Testa A, Jackson DB, Vaughn MG, et al. Incarceration as a unique social stressor during pregnancy: implications for maternal and newborn health. Soc Sci Med 2020;246:112777.

44 Turney K, Wildeman C. Detrimental for some? Heterogeneous effects of maternal incarceration on child wellbeing. Criminol Public Policy 2015;14:125-56

45 Wildeman C, Wang EA. Public health, and widening inequality in the USA. The Lancet 2017;389:1464-74.

46 Hatzenbuehler ML, Keyes K, Hamilton A, et al. The collateral damage of mass incarceration: risk of psychiatric morbidity among Nonincarcerated residents of High-Incarceration neighborhoods. Am $J$ Public Health 2015;105:138-43.

47 Blankenship KM, Del Rio Gonzalez AM, Keene DE, et al. Mass incarceration, race inequality, and health: expanding concepts and assessing impacts on well-being. Soc Sci Med 2018;215:45-52.
48 Giordano PC, Copp JE. "Packages" of risk. Criminol Public Policy 2015;14:157-68.

49 Arditti JA. Family process perspective on the heterogeneous effects of maternal incarceration on child wellbeing. Criminol Public Policy 2015;14:169-82.

50 LeFevre ML, U.S. Preventive Services Task Force. Screening for Chlamydia and gonorrhea: U.S. preventive services Task force recommendation statement. Ann Intern Med 2014;161:902-10.

51 Iritani BJ, Ford CA, Miller WC, et al. Comparison of self-reported and test-identified chlamydial infections among young adults in the United States of America. Sex Health 2006;3:245-51.

52 Rogers SM, Miller HG, Miller WC, et al. And chlamydial infections: different at-risk population subgroups? Sex Transmit Dis 2002:29:588-96.

53 Geller A, Jaeger K, Pace GT. Surveys, records, and the study of incarceration in families. Ann Am Acad Pol Soc Sci 2016;665:22-43.

54 Willems YE, Dolan CV, van Beijsterveldt CEM, et al. Genetic and environmental influences on self-control: assessing self-control with the ASEBA self-control scale. Behav Genet 2018;48:135-46.

55 Rodrigues DL, Prada M, Lopes D. Perceived sexual self-control and condom use with primary and casual sex partners: age and relationship agreement differences in a Portuguese sample. Psychol Health 2019;34:1231-49.

56 Thornton LC, Frick PJ, Ray JV, et al. Risky sex, drugs, sensation seeking, and Callous Unemotional traits in Justice-Involved male adolescents. J Clin Child Adolesc Psychol 2019;48:68-79. 